Article

\title{
Single Nano-Sized Metal-Organic Framework for Bio-Nanoarchitectonics with In Vivo Fluorescence Imaging and Chemo-Photodynamic Therapy
}

\author{
Yong-Mei Wang ${ }^{1}{ }^{\mathbb{D}}$, Ying $\mathrm{Xu}^{1}{ }^{1}$, Xinxin Zhang ${ }^{1}$, Yifan Cui ${ }^{1}$, Qingquan Liang ${ }^{1}$, Cunshun Liu ${ }^{1}$, Xinan Wang ${ }^{1}$, \\ Shuqi $\mathrm{Wu}^{2}$ and Rusen Yang ${ }^{1, *}$ (D) \\ 1 School of Advanced Materials and Nanotechnology, Academy of Advanced Interdisciplinary Research, \\ Xidian University, Xi'an 710126, China; wangym1001@xidian.edu.cn (Y.-M.W.); \\ 18141213000@stu.xidian.edu.cn (Y.X.); xxinzhang20@stu.xidian.edu.cn (X.Z.); \\ 17170210019@stu.xidian.edu.cn (Y.C.); 21010540018@stu.xidian.edu.cn (Q.L.); \\ 21141213493@stu.xidian.edu.cn (C.L.); wangxn@xidian.edu.cn (X.W.) \\ 2 School of Life Sciences, Northwest University of Technology, Xi'an 710072, China; sqwu@nwpu.edu.cn \\ * Correspondence: rsyang@xidian.edu.cn
}

check for updates

Citation: Wang, Y.-M.; Xu, Y.; Zhang, X.; Cui, Y.; Liang, Q.; Liu, C.; Wang, X.; Wu, S.; Yang, R. Single Nano-Sized Metal-Organic Framework for

Bio-Nanoarchitectonics with In Vivo Fluorescence Imaging and

Chemo-Photodynamic Therapy.

Nanomaterials 2022, 12, 287. https:// doi.org/10.3390/nano12020287

Academic Editor: Katsuhiko Ariga

Received: 7 December 2021

Accepted: 9 January 2022

Published: 17 January 2022

Publisher's Note: MDPI stays neutral with regard to jurisdictional claims in published maps and institutional affiliations.

Copyright: (c) 2022 by the authors. Licensee MDPI, Basel, Switzerland. This article is an open access article distributed under the terms and conditions of the Creative Commons Attribution (CC BY) license (https:// creativecommons.org/licenses/by/ $4.0 /)$.

\begin{abstract}
Theranostics is an emerging technique for cancer treatments due to its safety and high efficiency. However, the stability, efficiency, and convenience of preparation are the main challenges for developing theranostics. Here we describe a one-pot process for biocompatible metal-organic framework (MOF)-based theranostics. The ligand $\mathrm{H}_{2} \mathrm{~L}$ designed for the MOF enables both red fluorescence emission and photodynamic therapy (PDT). The frame and regular channel structure of $\mathrm{H}_{2} \mathrm{~L}-\mathrm{MOF}$ empower the theranostics with good drug delivery performance, and the uniform and nano-sized particles facilitate the in vivo imaging/therapy applications. In vivo fluorescence imaging and in vitro chemo-photodynamic therapy were achieved with the MOF without any further modification. Our results reveal an effective strategy to achieve multifunctional theranostics by the synergistic action of the organic ligand, metal node, and channel structure of MOF nanoparticles.
\end{abstract}

Keywords: metal-organic framework (MOF); multifunction; fluorescence; chemotherapy; photodynamic therapy

\section{Introduction}

Cancer is still a major disease that seriously imperils human life and health. The aging of a population, smoking, infection, and environmental pollution worsen the situation [1]. Chemotherapy, radiotherapy, and surgery are still the main treatments for cancer, notwithstanding their inevitable adverse effects [2,3]. The rapid and accurate diagnosis and effective treatment methods of tumors are still lacking and need to be developed.

The integration of both multimodal imaging agents and multiple therapeutic agents into theranostics is highly attractive and has been extensively studied for clinical applications. Theranostics uses imaging information to achieve time- and position-resolved therapy for a targeted tumor [4-6]. The key to this newly developed noninvasive diagnostic and therapeutic method is the preparation of probes with good imaging and therapy properties. Current research involves various strategies to achieve multi-functional theranostics probes, such as dopant modification [7], post-modification by subsequent chemical grafting [8], entrapping functional molecules in porous materials [9,10], and so on. For example, Luo et al. developed a core-shell nanomaterial-based all-in-one nanoplatform for in situ tumor imaging and simultaneous photothermal therapy [11]. However, the platform involves the preparation of nanobipyramids@polydopamine, gold clusters, and the composite of the two kinds of materials, which needs a complex preparation process and is time consuming. Meanwhile, as a commercialized anti-cancer drug, DOX has been 
widely used as a drug model to evaluate various kinds of nanocarriers' delivery and release effects $[4,12,13]$. Liu et al. developed the $\mathrm{CuS}_{\mathrm{NC}} @ \mathrm{DOX} @ \mathrm{MnO}_{2-\mathrm{NS}}$ nanoplatform for multi-mode imaging, chemical therapy, and photothermal therapy through layer-by-layer coating [14]. However, the current nanocarriers often involve complicated preparation processes for multifunctional probe materials, and the structural instability of the reported nanostructures is often a great concern.

Metal-organic frameworks (MOFs) are considered a promising material for theranostics, and are constructed from metal ions bridged by organic ligands and have a variety of structural types, low density, permanent pores, and ultra-high specific surface $[15,16]$. Their physical, chemical, and electrical properties can be easily tuned by incorporating different metal ions and organic ligands [17]. Nanocrystallization further expanded the applications in many fields, such as catalysis [18,19], gas storage and separation [20], sensing [21,22], bioimaging and therapy [23-25], and drug delivery [26-28]. The versatility of MOFs makes it possible to integrate multimodal imaging capability and target therapy functions in one single material by choosing appropriate building units. Chen et al. prepared $\mathrm{Ru}(\mathrm{bpy})_{3}{ }^{2+}$-incorporated UiO-67 NMOFs, which realized two-photon fluorescence imaging and photodynamic therapy [29]. It is a good method to realize multi-functional integration by constructing composite materials, but it involves complicated preparation processes and instability.

Herein, we propose a simple and cost-effective way to prepare multifunctional MOF nanoparticles for theranostics. Bis (2, 2'-bipyridy) (5, 5'-di-p-benzoicacid-[2, 2'] bipyridinyl) ruthenium (II) dichloride $\left(\mathrm{H}_{2} \mathrm{~L}\right)$ has the property of NIR-I fluorescence emission and singlet oxygen generation and is chosen as the organic ligand for the MOF. With biocompatible zirconium $\left(\mathrm{Zr}^{4+}\right)$ ions as the metal node, we constructed the porous and multifunctional $\mathrm{H}_{2} \mathrm{~L}-\mathrm{MOF}$ with a one-pot procedure and achieved nanoparticles that integrate NIR-I fluorescence imaging, photodynamic therapy, and drug delivery function in one material. The uniform $\mathrm{H}_{2} \mathrm{~L}-\mathrm{MOF}$ nanoparticles show a spherical shape, an average size of $50 \mathrm{~nm}$, and good dispersion in water. We verified the excellent biocompatibility of $\mathrm{H}_{2} \mathrm{~L}-\mathrm{MOF}$ by conducting cell experiments and in vivo safety evaluations of mice. In vivo red fluorescence imaging of both normal mice and tumor-bearing mice showed rapid metabolism through the liver and targeted tumor. Chemotherapy, photodynamic therapy, and chemophotodynamic therapy were demonstrated by cell experiments.

\section{Materials and Methods}

\subsection{Materials}

Zirconium tetrachloride $\left(\mathrm{ZrCl}_{4}\right)$ and (9,10-Anthracenediyl-bis(methylene)-dimalonic acid (ABDA) were both purchased from Aladdin Biochemical Technology Co., Ltd. (Shanghai, China). Bis (2, 2' - bipyridy) (5, 5'-Di-p-benzoicacid-[2, 2'] bipyridiny) ruthenium (II) dichloride $\left(\mathrm{H}_{2} \mathrm{~L}\right)$ was purchased from SunaTech Inc. (Suzhou, China). N, and N-dimethyl formamide (DMF) and dimethyl sulfoxide (DMSO) were both purchased from Tianjin Fuyu Fine Chemical Co., Ltd. (Tianjin, China). Trifluoroacetic acid (TFA) was purchased from Tianjin Kemeiou Chemical Reagent Co., Ltd. (Tianjin, China). DOX $\bullet \mathrm{HCl}$ was purchased from Beijing Huafeng Lianbo Chemical Materials Co., Ltd. (Beijing, China). 3-(4, 5-dimethythiazole-2yl)-2, 5-phenyl tetrazolium bromide (MTT) was purchased from Jiangsu Keygen Biotech Co., Ltd. (Nanjing, China). All reagents were used as received without further purification.

\subsection{Characterized Techniques}

The morphology and elemental analysis were examined using electron microscopy and energy-dispersive $\mathrm{X}$-ray spectroscopy (EDX). The morphology measurements were conducted using an Apreo+HiVac-scanning electron microscope (SEM, Thermo Fisher Scientific, Waltham, MA, USA) and a JEOL JEM-2100F (JEOL Ltd., Tokyo, Japan) transmission electron microscope (TEM). UV-Vis absorption spectra were recorded by a U-3900 visible spectrophotometer (Hitachi, Tokyo, Japan). The steady-state fluorescence spectra were obtained on an FL-4600 fluorescence spectrometer (Hitachi, Tokyo, Japan). The 
slit width was 5 and $5 \mathrm{~nm}$, and the excitation wavelength was $480 \mathrm{~nm}$. The infrared spectra (IR) were measured with a Nicolet $+\mathrm{iS}+50$ Fourier transform infrared spectrometer (Thermo Fisher Scientific, Waltham, MA, USA). XRD patterns were recorded with a Bruker D8 Advance X-ray diffraction analyzer (Bruker AXS, Karlsruhe, Germany) using $\mathrm{Cu}-\mathrm{K} \alpha$ radiation $(\lambda=1.5418 \AA$ ). Thermogravimetric analysis (TGA) was performed on an STA+449F5 TG-DTA analyzer (NETZSCH-Gerätebau GmbH, Bayern, Germany), and the heating process started from $20{ }^{\circ} \mathrm{C}$ at a ramp rate of $10{ }^{\circ} \mathrm{C} \mathrm{min}-1$ under air. The specific surface area was obtained by the Brunauer-Emmett-Teller (BET) calculation method. Pore size distributions were determined by the Barret-Joyner-Halenda (BJH) method from $\mathrm{N}_{2}$ adsorption-desorption isotherms, which were measured by accelerated surface area and porosimetry systems (Micromeritics ASAP 2460, Norcross, GA, USA).

\subsection{Cell Lines Culture and Animal Experiments}

Hela cells were obtained from American Type Culture Collection (ATCC), and then cultured in Dulbecco's Modified Eagle Medium (DMEM) containing 10\% FBS and 1\% penicillin/streptomycin at $37^{\circ} \mathrm{C}$ and under $5 \% \mathrm{CO}_{2}$. Nude mice (18-22 g) were obtained from the Institute of Hematology \& Hospital of Blood Disease, Chinese Academy of Medical Sciences \& Peking Union Medical College (No. SCXK-2016-0006, Tianjin, China). The mice had free access to both solid rodent chow and clean water. The Institutional Animal Care Committee of Northwest University of Technology approved all experimental protocols involving animals in the work.

\subsection{Preparation of $\mathrm{H}_{2} \mathrm{~L}-\mathrm{MOFS}$}

$\mathrm{H}_{2} \mathrm{~L}-\mathrm{MOF}$ s were synthesized with a simple solvothermal method. Zirconium tetrachloride $\left(\mathrm{ZrCl}_{4}\right)(2.3 \mathrm{mg}, 0.1 \mathrm{mmol})$ and $\mathrm{H}_{2} \mathrm{~L}(8.8 \mathrm{mg}, 0.1 \mathrm{mmol})$ were added in $10 \mathrm{~mL}$ DMF and $10 \mu \mathrm{L}$ TFA, which was fully dissolved by ultrasound for $10 \mathrm{~min}$. The mixed solution was then transferred into a Teflon-lined steel autoclave (Tianhe Keyan, Shandong, China) and heated at $100{ }^{\circ} \mathrm{C}$ for $72 \mathrm{~h}$. The orange-red powder $\mathrm{H}_{2} \mathrm{~L}-\mathrm{MOFs}$ were obtained after centrifugation, washing thoroughly with DMF and ethanol, and drying at room temperature.

\subsection{DOX Uptake Experiment}

Doxorubicin (DOX) loading efficiency was determined by mixing $\mathrm{H}_{2} \mathrm{~L}-\mathrm{MOFs}$ (10 $\mathrm{mg}$ ) and $\mathrm{DOX} \bullet \mathrm{HCl}(10 \mathrm{mg})$ in N-2-hydroxyethylpiperazine-N-ethane-sulphonicacid (HEPES) $(0.1 \mathrm{M}, 10 \mathrm{~mL})$. After being stirred for $48 \mathrm{~h}$ at room temperature, the mixture of the solution was centrifugated at $12,000 \mathrm{rpm}$ The supernatant solution was analyzed with a UV-vis spectrum at $480 \mathrm{~nm}$, and the mass (m) of DOX in the solution was calculated according to the UV standard curve of DOX. The loading efficiency was calculated according to the following formula:

$$
E_{\text {Load }}=\left(\mathrm{m}_{\text {DOx }}-\mathrm{m}\right) / \mathrm{m}_{\text {MOF }} \times 100 \%
$$

where $m_{\text {DOX }}$ means the mass of DOX's initial input $(10 \mathrm{mg})$, and $\mathrm{m}_{\mathrm{MOF}}$ means the mass of $\mathrm{H}_{2} \mathrm{~L}-\mathrm{MOFs}^{\prime}$ initial input $(10 \mathrm{mg})$.

\subsection{DOX Release Experiment}

The DOX-loaded $\mathrm{H}_{2} \mathrm{~L}-\mathrm{MOFs}\left(\mathrm{H}_{2} \mathrm{~L}-\mathrm{MOFs} @ \mathrm{DOX}\right.$ ) were put into an HEPES buffer $(0.1 \mathrm{M})$ solution with a $\mathrm{pH}$ of 7.2 and an HAc-NaAc buffer $(0.1 \mathrm{M})$ solution with a $\mathrm{pH}$ of 5.1 to imitate the environment in healthy tissue and in tumor tissue. After the drug released for $3,6,9,14,24,36$ and $48 \mathrm{~h}$, the amounts of released DOX in the solution were measured by UV-vis standard-curve spectrophotometry at $480 \mathrm{~nm}$ after centrifugation. The release efficiency was calculated based on the following equation:

$$
E_{\text {Release }}=\mathrm{m}_{\text {DOx }}{ }^{\prime} /\left(\mathrm{m}_{\text {DOX }}\right) \times 100 \%
$$

where $\mathrm{m}_{\mathrm{DOx}}$ ' means the mass of DOX released from $\mathrm{H}_{2} \mathrm{~L}-\mathrm{MOFs} @ \mathrm{DOX}$ and $\mathrm{m}_{\mathrm{DOX}}$ means the mass of DOX loaded in $\mathrm{H}_{2} \mathrm{~L}-\mathrm{MOF}$. 


\subsection{In Vitro Singlet Oxygen Generation}

The tumor microenvironment is characterized by a high level of hydrogen peroxide $\left(\mathrm{H}_{2} \mathrm{O}_{2}\right)$ and weak acidity due to intense metabolic activities. $\mathrm{H}_{2} \mathrm{O}_{2}$ could react with a photosensitizer to produce singlet oxygen $\left({ }^{1} \mathrm{O}_{2}\right)[30,31]$. The ${ }^{1} \mathrm{O}_{2}$ generation of $\mathrm{H}_{2} \mathrm{~L}-\mathrm{MOFs}$ upon laser irradiation was conducted using an ABDA method. ${ }^{1} \mathrm{O}_{2}$ generated from the $\mathrm{H}_{2} \mathrm{~L}-\mathrm{MOF}$ oxidizes ABDA and decreases ABDA's UV absorbance at $380 \mathrm{~nm}$. In this study, the mixed solution of $80 \mu \mathrm{M} \mathrm{H}_{2} \mathrm{~L}-\mathrm{MOF}$ (in saline) and $200 \mu \mathrm{M}$ ABDA were irradiated with an LED lamp (light intensity $100 \mathrm{~mW} \mathrm{~cm}^{-2}$ ). The absorbance spectra of the solutions were recorded at each predetermined time interval. The stability of ABDA in PBS and $\mathrm{H}_{2} \mathrm{~L}-\mathrm{MOF}$ in saline under irradiation were also tested as control experiments.

\subsection{Cytotoxicity and In Vitro Chemotherapy, Photodynamic Therapy, and Chemo-Photodynamic Therapy of $\mathrm{H}_{2} \mathrm{~L}-\mathrm{MOFS}$}

The cytotoxicity of $\mathrm{H}_{2} \mathrm{~L}-\mathrm{MOF}$ nanoparticles was evaluated by the viability of Hela cells using a standard methyl thiazolyl tetrazolium (MTT) assay. Briefly, Hela cells were incubated into 96-well cell culture plates with a density of $5 \times 10^{3}$ cells per well. Two groups of $\mathrm{H}_{2} \mathrm{~L}-\mathrm{MOF}$ and $\mathrm{H}_{2} \mathrm{~L}-\mathrm{MOF} @ \mathrm{DOX}$ were introduced to the medium at concentrations of $5,15,20,40$, and $80 \mu \mathrm{g} / \mathrm{mL}$ and incubated for $8 \mathrm{~h}$ after the Hela cells reached 90-95\% confluence. After being washed three times in PBS solution, the photodynamic therapy (PDT) groups were irradiated with a blue-emission LED lamp $\left(100 \mathrm{~mW} \mathrm{~cm}^{-2}\right)$ for $10 \mathrm{~min}$. Then, the plates were kept in an incubator under $37{ }^{\circ} \mathrm{C}$ and $5 \% \mathrm{CO}_{2}$ for another $24 \mathrm{~h}$. Then, MTT (3-(4,5-dimethyl-2-thiazolyl)-2,5-diphenyl-2-H-tetrazolium bromide) solution $(20 \mu \mathrm{L} 5.0 \mathrm{mg} / \mathrm{mL}, \mathrm{BBS})$ was successively added into each well. After $3 \mathrm{~h}$, the remaining MTT solutions were removed. Then, in order to dissolve the formazan crystals, $150 \mu \mathrm{L}$ dimethyl sulfoxide (Amresco, Albany, NY, USA) was added into each well. The absorbance of each well (OD value) was measured by a microplate reader (Promega, Beijing, China) at a wavelength of $550 \mathrm{~nm}$. The cell viability was calculated as follows:

$$
\text { Cell viability } \%=\left(\mathrm{OD}_{\text {drug }} / \mathrm{OD}_{\text {control }}\right) \times 100 \%
$$

\subsection{In Vivo Fluorescence Imaging}

In vivo fluorescence imaging was performed with nude mice as models. The mice were anesthetized with $4 \%$ chloral hydrate $\left(6 \mathrm{~mL} \mathrm{~kg}^{-1}\right)$. After the intravenous injection of $\mathrm{H}_{2} \mathrm{~L}-\mathrm{MOF}$ solution $(20 \mu \mathrm{mol} \mathrm{Zr}$ per $\mathrm{kg}$ ), the fluorescence images were obtained by positioning the mice on the animal plate in the in vivo imaging system (NightOWL LB 983, Berthold Technologies GmbH \& Co. KG, Bad Wildbad, Germany). The excitation and emission wavelengths were 480 and $646 \mathrm{~nm}$, respectively. The data were obtained with IndiGO software (Vector, Stuttgart, Germany).

\section{Results}

\subsection{Synthesis and Characterization of $\mathrm{H}_{2} \mathrm{~L}-\mathrm{MOFS}$}

$\mathrm{H}_{2} \mathrm{~L}$ and its derivatives have been used as ligands to construct bulk MOFs for catalysis application [32,33]. By slightly adjusting the reaction condition, we successfully prepared uniform $\mathrm{H}_{2} \mathrm{~L}-\mathrm{MOF}$ nanospheres by treating $\mathrm{ZrCl}_{4}$ and $\mathrm{H}_{2} \mathrm{~L}$ in DMF and TFA (Figure 1a). The size and shape of MOF particles is important for their in vivo application [34]. By adjusting the ratio of DMF and TFA, monodisperse nanoparticles with an average diameter of $50 \mathrm{~nm}$ were achieved (Figure $1 \mathrm{~b}, \mathrm{c}$ and Figure S1). The nanosized $\mathrm{H}_{2} \mathrm{~L}-\mathrm{MOF}$ showed good dispersion in water. The element mapping in Figure $1 \mathrm{~d}$ and Figure S2 showed the uniform distribution of $\mathrm{Zr}$ and $\mathrm{Ru}$ elements in $\mathrm{H}_{2} \mathrm{~L}-\mathrm{MOF}$ nanoparticles. The powder X-ray diffraction (XRD) pattern (Figure S3) shows a significant amorphous component in $\mathrm{H}_{2} \mathrm{~L}$ MOFs, and the main peaks in 3.9 and 7.6 degrees for the crystalline component match the simulated pattern [32]. The wide peak at 20 degrees is mainly due to the scattering effect of $\mathrm{H}_{2} \mathrm{~L}-\mathrm{MOF}$ nanoparticles. Discontinuous, anisotropic small lattices shown in the highresolution transmission electron microscope (HRTEM) images (Figure S4) confirm that these 
MOF nanoparticles are partially crystallized. Both the HRTEM and XRD measurements illustrate that $\mathrm{H}_{2} \mathrm{~L}-\mathrm{MOF}$ have short-ordered structures [35]. Thermogravimetric analysis (TGA) was used to investigate the thermal stability of the $\mathrm{H}_{2} \mathrm{~L}-\mathrm{MOF}$ (Figure S5). The weight loss of $5.5 \%$ in the range of $60-150{ }^{\circ} \mathrm{C}$ was attributed to the removal of the solvents' $\mathrm{DMF}$ and water molecule. The structure remained stable up to $350{ }^{\circ} \mathrm{C}$. EDS relative element content showed the rough content of $\mathrm{C}, \mathrm{N}$, and $\mathrm{O}$ elements, and also $\mathrm{Ru}$ and $\mathrm{Zr}$ metallic elements derived from the ligand $\mathrm{H}_{2} \mathrm{~L}$ and metal node $\mathrm{Zr}^{4+}$, respectively. The porosity of $\mathrm{H}_{2} \mathrm{~L}-\mathrm{MOF}$ was verified by $\mathrm{N}_{2}$ adsorption measurement (Figure S7). Nitrogen adsorption indicated that the Brunauer-Emmett-Teller (BET) surface area of the $\mathrm{H}_{2} \mathrm{~L}-\mathrm{MOF}$ was $61.77 \mathrm{~m}^{2} \mathrm{~g}^{-1}$ (Figure $\mathrm{S7a}$ ). $\mathrm{H}_{2} \mathrm{~L}-\mathrm{MOF}$ exhibited a type IV $\mathrm{N}_{2}$ adsorption-desorption isotherm, which may have resulted from the existence of pores of different sizes. The not very high $\mathrm{N}_{2}$ uptake capacity may be attributed to the side chain of bipyridine ruthenium. Pore size distribution showed $1.8 \mathrm{~nm}$ and $3.1 \mathrm{~nm}$ pores (Figure S7b). However, the large pore size of $\mathrm{H}_{2} \mathrm{~L}-\mathrm{MOF}$ is conducive to delivering molecules with large molecule sizes (Figure 1a).
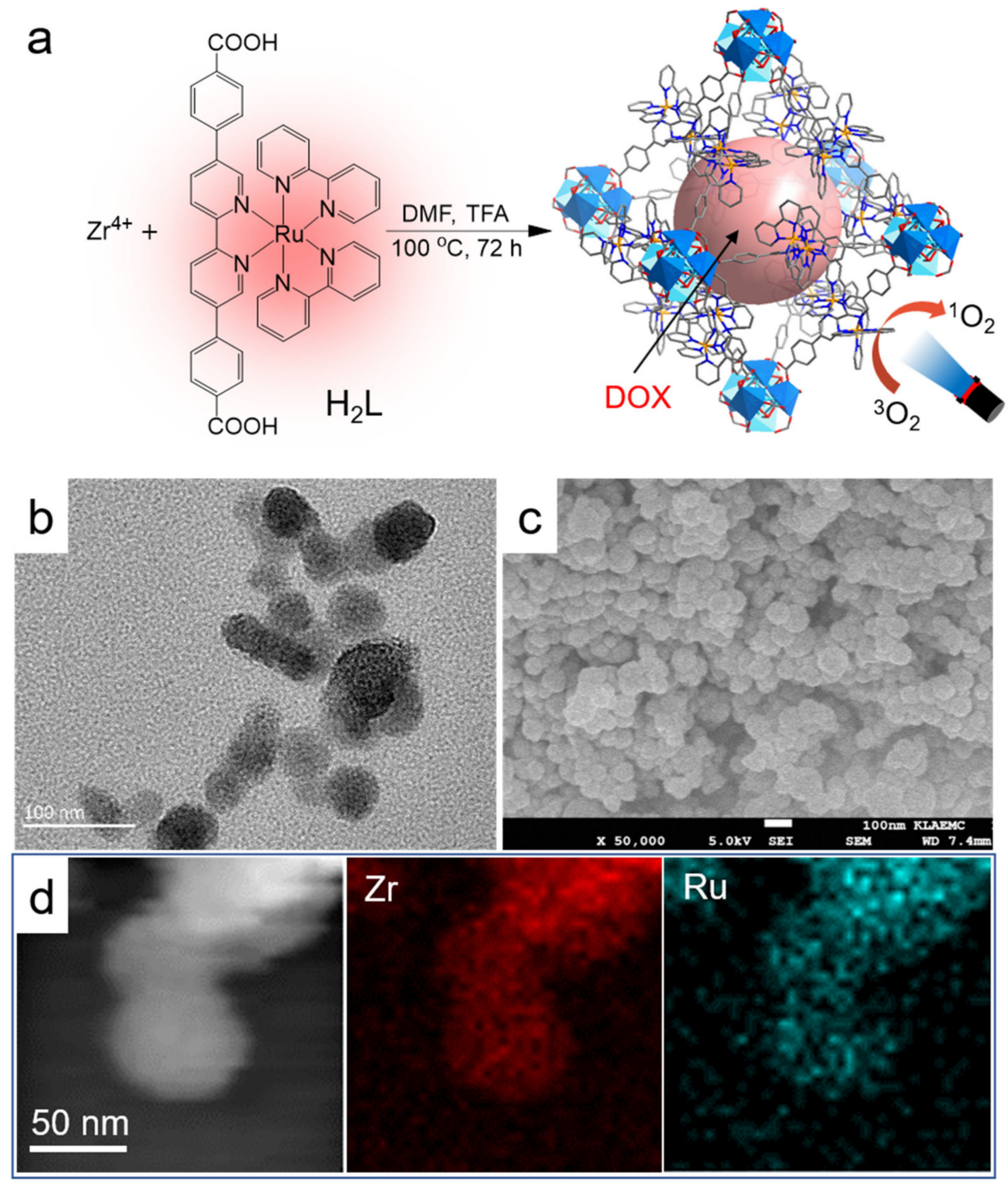

Figure 1. Structure and chemical composition analysis of $\mathrm{H}_{2} \mathrm{~L}-\mathrm{MOF}$ nanoparticles. (a) The schematic illustration of the synthesis of $\mathrm{H}_{2} \mathrm{~L}-\mathrm{MOFs}$, uptake of drug for chemotherapy, and the processes of light-triggered singlet oxygen generation for PDT. (b)TEM image, (c) SEM image, and (d) STEM image and EDS elemental mapping of $\mathrm{H}_{2} \mathrm{~L}-\mathrm{MOF}$. 


\subsection{Optical Properties of $\mathrm{H}_{2} \mathrm{~L}-\mathrm{MOFs}$}

The optical properties of $\mathrm{H}_{2} \mathrm{~L}-\mathrm{MOF}$ were investigated for their optical imaging and photodynamic therapy ability. As shown in Figure 2a, the $\mathrm{H}_{2} \mathrm{~L}-\mathrm{MOF}$ showed a strong red emission at $646 \mathrm{~nm}$ in water, and the fluorescence spectrum remained almost unchanged after they were stored for 30 days at room temperature and with room light exposure. The red emission of the $\mathrm{H}_{2} \mathrm{~L}-\mathrm{MOFs}$ is advantageous to circumvent the disturbance from auto-fluorescence and avoid the scattering light of tissue, which facilitates realizing low background imaging [36]. The good emission stability illustrates the long-term stability of $\mathrm{H}_{2} \mathrm{~L}-\mathrm{MOF}$.
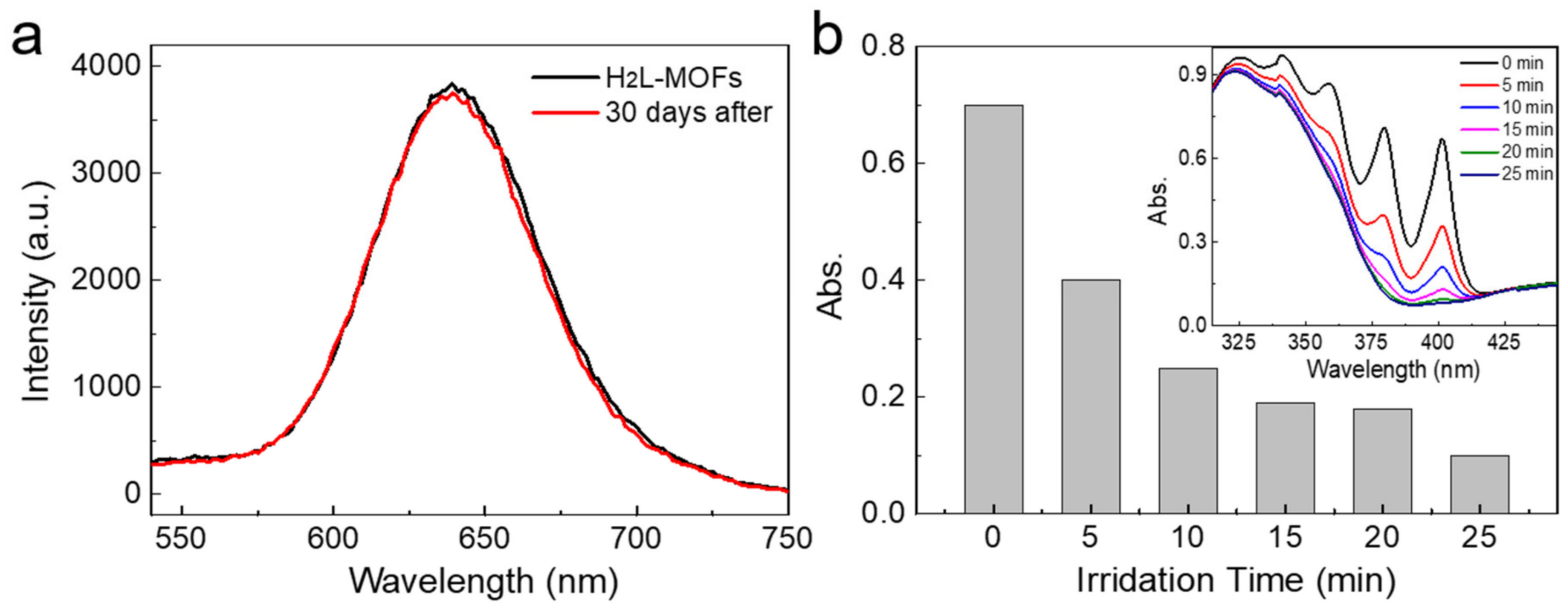

Figure 2. Optical properties of $\mathrm{H}_{2} \mathrm{~L}-\mathrm{MOF}$ nanoparticles. (a) The fluorescence spectrum of $\mathrm{H}_{2} \mathrm{~L}-\mathrm{MOF}$ nanoparticles right after the growth and 30 days after the growth. (b) The UV-vis absorbance intensity of ABDA at $380 \mathrm{~nm}$ after the addition of $\mathrm{H}_{2} \mathrm{~L}-\mathrm{MOF}$ and under irradiation for different time periods. Inset: the corresponding UV-vis absorption spectra of the mixture of $\mathrm{ABDA}$ and $\mathrm{H}_{2} \mathrm{~L}-\mathrm{MOF}$ under different irradiation time periods.

The derivatives of bipyridine ruthenium complex have been verified with excellent singlet oxygen $\left({ }^{1} \mathrm{O}_{2}\right)$ generation [30,31]. ABDA can be used as an indicator to determine the singlet oxygen generation, as it can react with singlet oxygen to decrease its absorbance at $380 \mathrm{~nm}[37,38]$. The absorbance of the mixture of $\mathrm{H}_{2} \mathrm{~L}-\mathrm{MOF}$ and ABDA attenuated $97 \%$ in only $20 \mathrm{~min}$ when irradiated with light (Figure $2 \mathrm{~b}$ ). Meanwhile, the absorbance of both $\mathrm{H}_{2} \mathrm{~L}-\mathrm{MOF}$ and $\mathrm{ABDA}$ showed a high tolerance to the irradiation, illustrating that the attenuation is ascribed to the ${ }^{1} \mathrm{O}_{2}$ produced by $\mathrm{H}_{2} \mathrm{~L}-\mathrm{MOFs}$ (Figure S8). The results illustrate the high ${ }^{1} \mathrm{O}_{2}$ generation efficiency of $\mathrm{H}_{2} \mathrm{~L}-\mathrm{MOFs}$ and high PDT efficiency, which is higher than the analogues $\mathrm{Ru}\left[4,4^{\prime}-(\mathrm{COOH})_{2} \mathrm{bpy}\right]_{3}{ }^{2+}$ based MOFs we reported before [35].

\subsection{Drug Loading and Releasing of $\mathrm{H}_{2} \mathrm{~L}-\mathrm{MOFS}$}

Porous nanomaterials are excellent drug delivery carriers [10,12]. The large pores of $\mathrm{H}_{2} \mathrm{~L}-\mathrm{MOFs}$ make it a potential drug delivery carrier. Thus, we selected a commercialized anticancer drug, DOX, to investigate the drug adsorption and $\mathrm{pH}$-responsive release properties of $\mathrm{H}_{2} \mathrm{~L}-\mathrm{MOF}$. The loading efficiency of DOX was verified to be as high as $94 \%$ after $48 \mathrm{~h}$ uptake (Figure S9). The high loading efficiency is attributed to the combination of electrostatic and noncovalent interactions, including $\pi-\pi$ stacking effects and hydrophobic interactions [39]. In the simulated approximate normal physiological environment ( $\mathrm{pH}$ 7.2), the release rate of DOX reached $53 \%$ in $10 \mathrm{~h}$ (Figure 3). In comparison, tumor cells tend to create an acidic extracellular environment, and in an acidic solution (pH 5.1) used to approximately simulate the tumor cell environment, the releasing rate reached $80 \%$ in $10 \mathrm{~h}$. The controlled release of DOX may be attributed to the blocking buffer effect of the side chain bipyridine ruthenium group on the ligand $\mathrm{H}_{2} \mathrm{~L}$. The large side chain has both steric hindrance and weak hydrogen bonds with DOX from protecting DOX to burst 
release from the pore aperture of $\mathrm{H}_{2} \mathrm{~L}-\mathrm{MOF}$. Minati et al. reported that the polyelectrolyte complex layer coated mesoporous silica nanoparticles (MSN) for controlled drug release in cellular environment [12]. The work realized a delicately controlled drug release through the PAA/PAH complex layer. However, MSN usually has no imaging ability and can only be used as a drug delivery carrier alone. Thus, the $\mathrm{pH}$-responsive release properties endow $\mathrm{H}_{2}$ L-MOFs' imaging nanoparticles with smart drug delivery capability for theranostics.

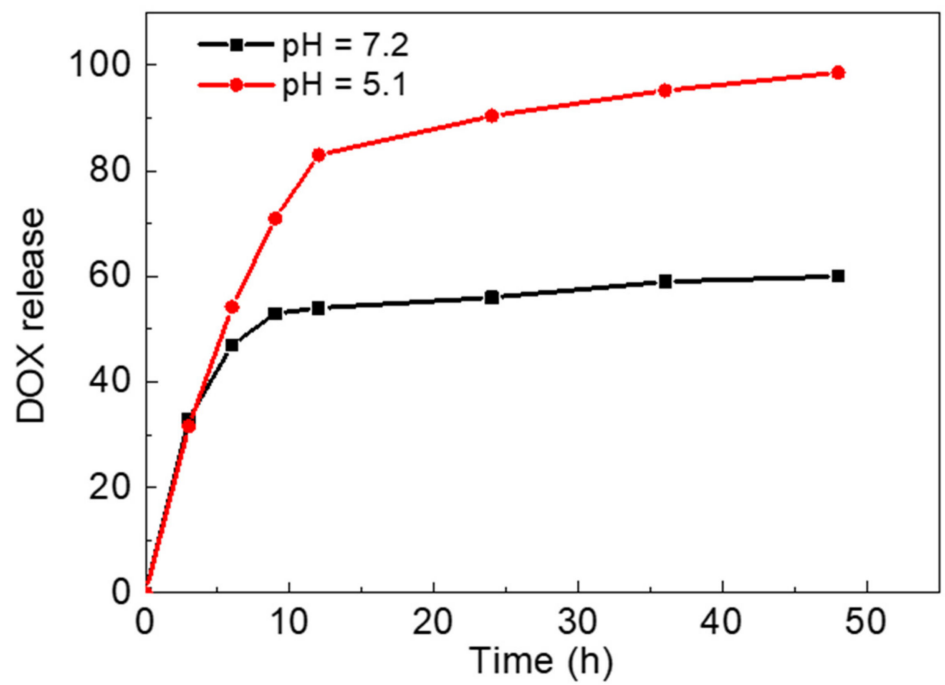

Figure 3. Release rate of DOX in buffer at $\mathrm{pH}=5.1$ and $\mathrm{pH}=7.2$.

\subsection{Biocompatibility of $\mathrm{H}_{2} \mathrm{~L}-\mathrm{MOFS}$}

The cytotoxicity of $\mathrm{H}_{2} \mathrm{~L}-\mathrm{MOF}$ was tested with Hela cells using the standard 3-(4,5dimethylthiazol-2-yl)-2,5-diphenyltetrazolium bromide (MTT) assay. The cell viability of Hela cells (a human cervical carcinoma cell line) was recorded after incubation with $\mathrm{H}_{2} \mathrm{~L}$ MOFs for $8 \mathrm{~h}$ (Figure $4 \mathrm{a}$ ). The viability of cells did not decline after the incubation in the presence of 20 ppm $\mathrm{H}_{2} \mathrm{~L}-\mathrm{MOF}$ (Figure $4 \mathrm{a}$ ). More than $82 \%$ cell viability was observed with 80 ppm $\mathrm{H}_{2}$ L-MOFs. Thus, $\mathrm{H}_{2}$ L-MOFs are biocompatible and biosafe at the cellular level.

In vivo toxicity of $\mathrm{H}_{2} \mathrm{~L}-\mathrm{MOF}$ was evaluated by growth observation of the main organs of the mice after the $\mathrm{H}_{2} \mathrm{~L}-\mathrm{MOF}$ treatment. After the intravenous injection of $\mathrm{H}_{2} \mathrm{~L}-\mathrm{MOF}$ nanoparticles, the weight and behavior of the mice were monitored and observed for a month. The weight of the mice increased during the following 4 weeks (Figure $4 \mathrm{~b}$ ), and none of the mice died. Meanwhile, histological changes in the main organs (liver, heart, spleen, intestine, kidney, and lung) of the mice two weeks after injection were examined to reveal the effect of $\mathrm{H}_{2} \mathrm{~L}-\mathrm{MOF}$ nanoparticles on the mice (Figure $4 \mathrm{c}$ ). As shown in Figure $4 \mathrm{c}$, no significant histological changes were observed between the control and the experimental groups, and no tissue damages were found upon $\mathrm{H}_{2} \mathrm{~L}-\mathrm{MOF}$ injection. The in vivo results demonstrate that $\mathrm{H}_{2} \mathrm{~L}-\mathrm{MOF}$ are highly biocompatible.

\subsection{In Vitro Treatment of $\mathrm{H}_{2} \mathrm{~L}-\mathrm{MOFS}$}

The viability of Hela cells was measured to evaluate the in vitro PDT and DOX-release chemotherapy efficiency of $\mathrm{H}_{2} \mathrm{~L}-\mathrm{MOF}$ using a standard MTT assay. The cell viability was recorded after incubation with $\mathrm{H}_{2} \mathrm{~L}-\mathrm{MOF}$ for $8 \mathrm{~h}$ (Figure 5). The PDT-related groups were irradiated with a light of $480 \mathrm{~nm}$ for $10 \mathrm{~min}\left(0.1 \mathrm{~W} / \mathrm{cm}^{2}\right)$. The cell viability of the only $\mathrm{H}_{2} \mathrm{~L}-\mathrm{MOF}$-treated groups in all dosages was higher than $85 \%$, indicating their high in vitro biocompatibility (Figure 5a blue). The viability of PDT-treated Hela cells was less than $85 \%$, which confirmed the PDT efficiency of $\mathrm{H}_{2} \mathrm{~L}-\mathrm{MOF}$ (Figure $5 \mathrm{a}$ pink). The smart delivery and release of DOX resulted in the chemotherapy group with a lower viability (70\%) (Figure 5b blue). As a result, a low 50\% inhibiting concentration (IC50) (20 ppm) and high cell lethality (80\%) were observed following co-therapy of $\mathrm{H}_{2} \mathrm{~L}-\mathrm{MOFs} @ \mathrm{DOX}$ under 
irritation (Figure 5b pink). The high biocompatibility may be ascribed to the nanoscale of $\mathrm{H}_{2} \mathrm{~L}-\mathrm{MOF}$; the small size and approximate spherical morphology facilitate the successful uptake and metabolism [40]. The characteristics of easy uptake and metabolism further promote the PDT and chemotherapy efficiency.
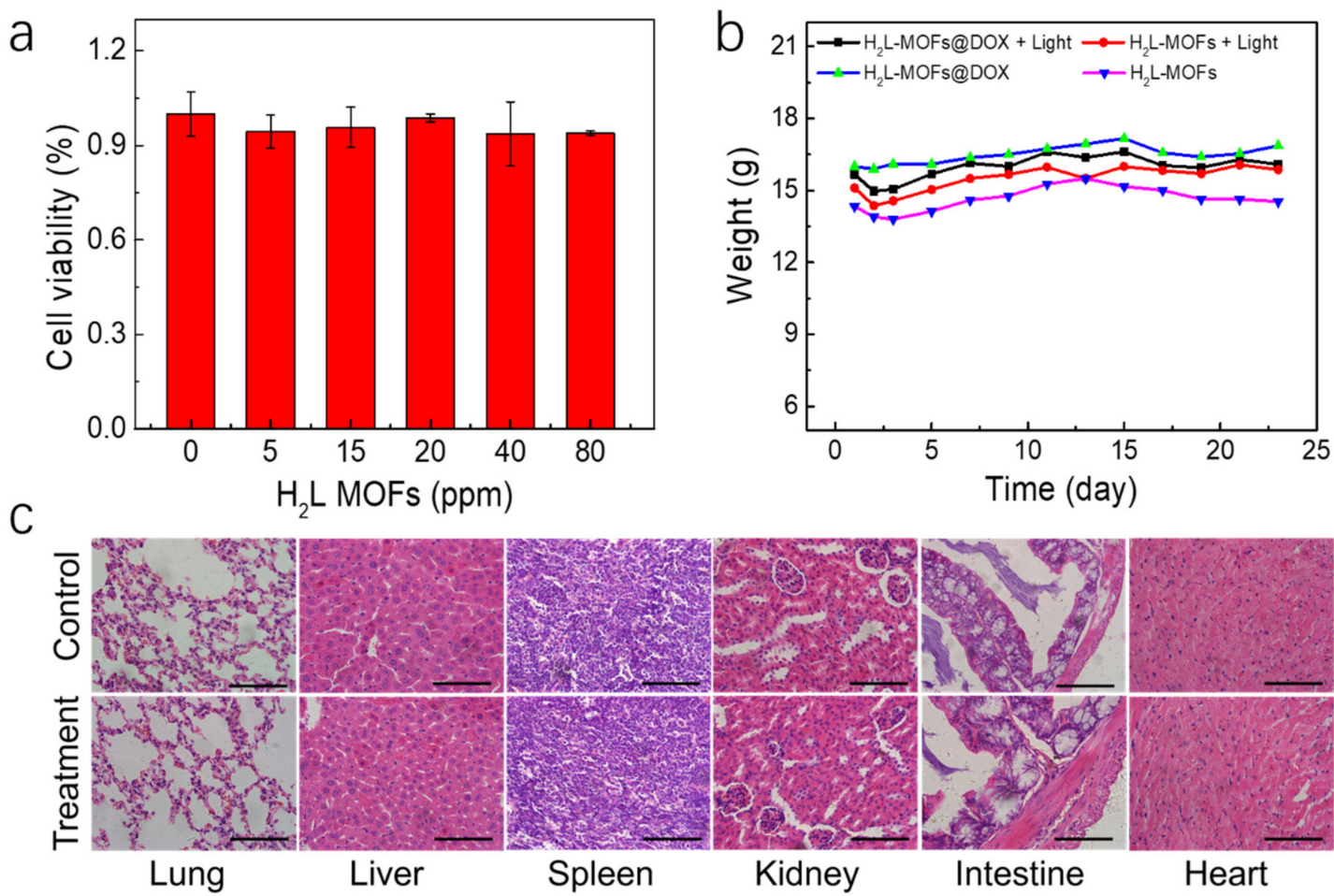

Figure 4. Biocompatibility study of $\mathrm{H}_{2} \mathrm{~L}-\mathrm{MOF}$ nanoparticles. (a) Viability of Hela cells incubated for $8 \mathrm{~h}$ in the presence of $\mathrm{H}_{2} \mathrm{~L}-\mathrm{MOF}$ with different concentrations. (b) The body weight trends of the mice injected with $\mathrm{H}_{2} \mathrm{~L}-\mathrm{MOFs}$ and $\mathrm{H}_{2} \mathrm{~L}-\mathrm{MOFs} @ \mathrm{DOX}(20 \mu \mathrm{mol} \mathrm{Zr}$ per kg). (c) Histological images of the lung, liver, spleen, kidney, intestine, and heart of mice after injection with saline solution (control) and $\mathrm{H}_{2} \mathrm{~L}-\mathrm{MOFs}$ (treatment, $20 \mu \mathrm{mol} \mathrm{Zr}$ per kg). Scale bars: $100 \mu \mathrm{m}$.
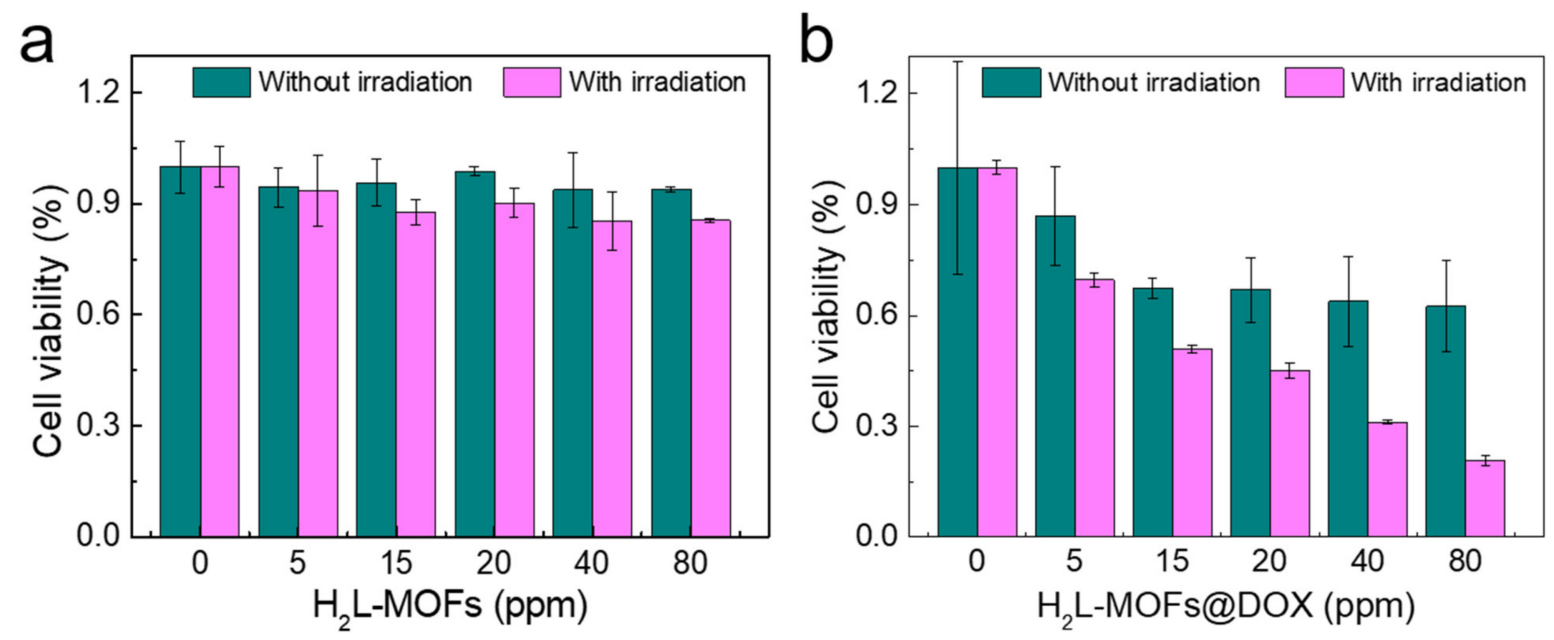

Figure 5. Cell viability of (a) $\mathrm{H}_{2} \mathrm{~L}-\mathrm{MOF}$ and (b) $\mathrm{H}_{2} \mathrm{~L}-\mathrm{MOFs} @ D O X$.

3.6. In Vivo Fluorescence Imaging of $\mathrm{H}_{2} \mathrm{~L}-\mathrm{MOFS}$

The imaging efficiency and biodistribution of $\mathrm{H}_{2} \mathrm{~L}-\mathrm{MOF}$ in mice were evaluated by real-time fluorescence imaging. After the intravenous injection of the $\mathrm{H}_{2} \mathrm{~L}-\mathrm{MOF}$ into mice $(20 \mu \mathrm{mol} \mathrm{Zr}$ per $\mathrm{kg})$, the fluorescence signals were recorded instantly (Figure 6). Increased 
fluorescence signals of $\mathrm{H}_{2} \mathrm{~L}-\mathrm{MOF}$ were observed in the liver in the first $24 \mathrm{~h}$ despite being acquired through intact skin and the skull. Then, the fluorescence signals transferred to the intestine from 24 to $48 \mathrm{~h}$. Finally, the $\mathrm{H}_{2} \mathrm{~L}-\mathrm{MOF}$ accumulated in the bladder from 48 to $72 \mathrm{~h}$ after injection (Figure 6). The $\mathrm{H}_{2} \mathrm{~L}-\mathrm{MOF}$ were then observed to be excreted from the mice through urine. The fluorescence signal vanished about $84 \mathrm{~h}$ after the injection. The imaging results validated safe metabolism and the high sensitivity of the $\mathrm{H}_{2} \mathrm{~L}-\mathrm{MOF}$ as a fluorescence imaging probe. The successful metabolism in mice also indicates the good biological safety of the material.

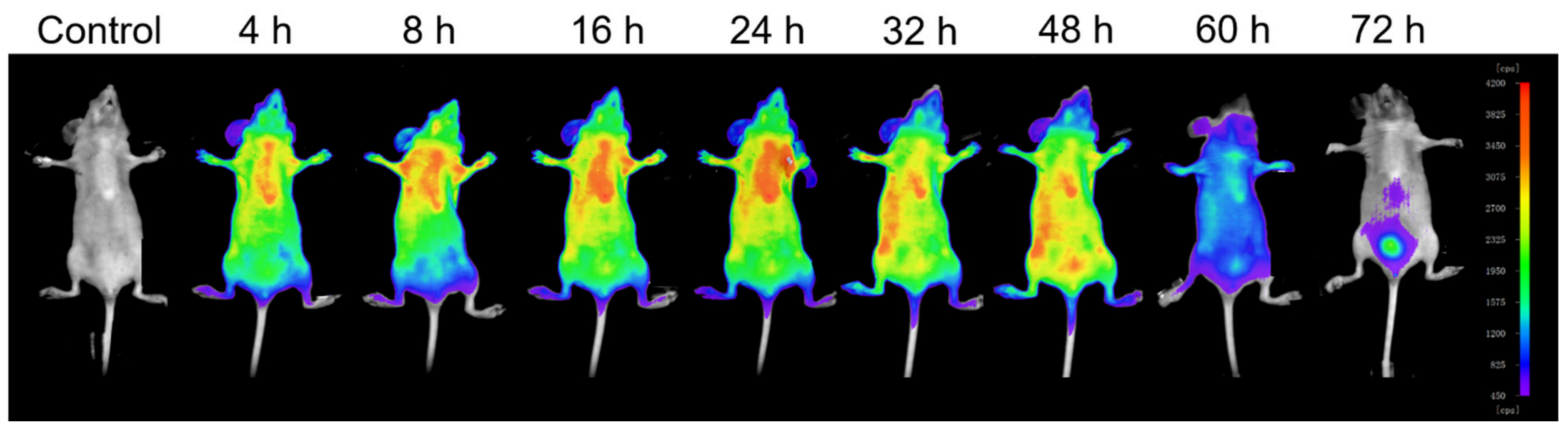

Figure 6. Fluorescence imaging of a normal nude mouse recorded before and after injection of $\mathrm{H}_{2}$ L-MOFs.

Fluorescence images with Hela tumor-bearing mice as models were recorded using $\mathrm{H}_{2} \mathrm{~L}-\mathrm{MOF}$ nanoparticles as imaging probes to demonstrate the in vivo tumor imaging diagnosis and imaging-guided therapy ability. The fluorescence signals of the $\mathrm{H}_{2} \mathrm{~L}-\mathrm{MOF}$ appeared at the tumor site and liver of the mice because of the enhanced permeability and retention (EPR) effect [41,42] (Figure 7). The tumors were significantly distinguished from surrounding tissues, and the fluorescence intensity in the tumors maintained for $60 \mathrm{~min}$ (Figure 7). Thus, the tumor was clearly visualized with the fluorescence images, despite being acquired through intact skin and the skull. The fluorescence images of the dissected tumor validate the passive tumor targeting of $\mathrm{H}_{2} \mathrm{~L}-\mathrm{MOF}$ (Figure $\mathrm{S} 10$ ). Thus, combining the good in vitro PDT and chemotherapy ability of $\mathrm{H}_{2} \mathrm{~L}-\mathrm{MOF}, \mathrm{H}_{2} \mathrm{~L}-\mathrm{MOF}$ could be used for imaging diagnosis and imaging-guided therapy of tumors.

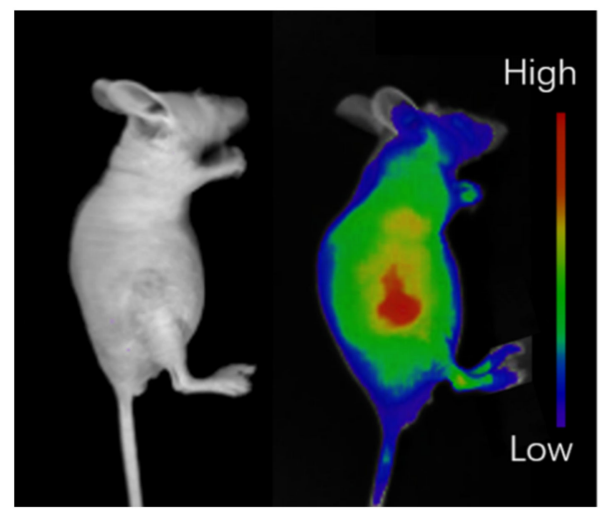

Figure 7. Fluorescence imaging of tumor sites in nude mice bearing tumors.

\section{Conclusions}

In summary, the biocompatible multifunctional $\mathrm{H}_{2} \mathrm{~L}-\mathrm{MOF}$ were successfully developed by using zirconium ion and the long-molecule-structure ligand $\mathrm{H}_{2} \mathrm{~L}$ as building units. Under single-wavelength excitation, simultaneous NIR-I fluorescence and singlet oxygen $\left({ }^{1} \mathrm{O}_{2}\right)$ generation were achieved, which showed the fluorescence imaging and photodynamic therapy potential. Moreover, the long-molecule structure of the ligand endows 
the $\mathrm{H}_{2} \mathrm{~L}-\mathrm{MOF}$ with a large pore structure, which realized $94 \%$ DOX uptake. In vitro drug delivery tests further validated the drug delivery and sustained release. In vitro MTT cytotoxicity experiments showed efficient photodynamic therapy and chemotherapy through drug delivery. In vivo normal mice and tumor-bearing mice imaging validated the fluorescence imaging diagnosis capability of the $\mathrm{H}_{2} \mathrm{~L}-\mathrm{MOF}$. The report demonstrates a method for the convenient construction of theranostics probes.

Supplementary Materials: The following supporting information can be downloaded at: https:// www.mdpi.com/article/10.3390/nano12020287/s1, Figure S1: Size distribution obtained from SEM images of H2L-MOFs; Figure S2. (a) SEM image and elemental mapping of (b) overlapped, (c) Zr, (d) Ru of the H2L-MOFs; Figure S3. XRD of H2L-MOFs; Figure S4. High Resolution Transmission Electron Microscope (HRTEM) image of H2L-MOFs nanoparticles; Figure S5. TGA plots of H2LMOFs; Figure S6. EDS spectrum of H2L-MOFs; Figure S7. N2 adsorption isotherms for H2L-MOFs at $77 \mathrm{~K}$. (a) N2 adsorption isotherms and (b) DFT pore size distribution for H2L-MOFs using data measured with N2 at $77 \mathrm{~K}$; Figure S8. Control groups of (a) $200 \mu \mathrm{M}$ ABDA and (b) $80 \mu \mathrm{M}$ H2L-MOFs with the irradiation over a period of 25 min; Figure S9. DOX adsorption of MOFs. (a) Absorbance of DOX with different concentrations. (b) Standard curve of DOX solution. (c) DOX absorbance spectrum of H2L-MOFs after $48 \mathrm{~h}$ DOX adsorption; Figure S10. Fluorescence and intensity diagrams of various organs in nude mice bearing tumor. (a) stomach, lung, tumor, and intestine. (b) spleen, liver, kidney, and heart; Table S1. Relative element content obtained by EDS.

Author Contributions: Conceptualization, Y.-M.W. and X.W.; methodology, Y.-M.W., Q.L. and Y.X.; validation, X.Z., Y.C., C.L. and Y.X.; formal analysis, Y.-M.W. and Y.X.; investigation, Y.-M.W. and C.L.; resources, X.Z. and R.Y.; data curation, Y.C., Q.L. and S.W.; writing-original draft preparation, Y.-M.W., X.Z., C.L. and Y.X.; writing-review and editing, Y.-M.W. and R.Y.; visualization, X.W.; supervision, S.W. and R.Y.; project administration, R.Y.; funding acquisition, R.Y. All authors have read and agreed to the published version of the manuscript.

Funding: This research was funded by the National Natural Science Foundation of China under Grant No. 51973170, the Fundamental Research Funds for the Central Universities (No. JB191405 and JC2017), the Natural Science Foundation of Shaanxi Province (No. 2019JCW-17 and 2020JCW-15), and the Development and Planning Guide Foundation of Xidian University (Grant No. 21103200005).

Institutional Review Board Statement: The animal study protocol was approved by the Ethics Committee of Northwest University of Technology (No. 202101007, 3 March 2021).

Informed Consent Statement: Not applicable.

Data Availability Statement: Data can be available upon request from the authors.

Acknowledgments: We thank Xidian University, Nankai University, and Xue-Bo Yin for their support.

Conflicts of Interest: The authors declare no conflict of interest.

\section{References}

1. Shah, S.C.; Kayamba, V.; Peek, R.M., Jr.; Heimburger, D. Cancer control in low-and middle-income countries: Is it time to consider screening? J. Glob. Oncol. 2019, 5, 1-8. [CrossRef] [PubMed]

2. Hauer-Jensen, M.; Denham, J.W.; Andreyev, H.J.N. Radiation enteropathy-Pathogenesis, treatment and prevention. Nat. Rev. Gastroenterol. Hepatol. 2014, 11, 470-479. [CrossRef] [PubMed]

3. Szczesniak, M.M.; Maclean, J.; Zhang, T.; Graham, P.H.; Cook, I.J. Persistent dysphagia after head and neck radiotherapy: A common and under-reported complication with significant effect on non-cancer-related mortality. Clin. Oncol. 2014, 26, 697-703. [CrossRef] [PubMed]

4. $\quad$ Liu, W.; Wang, Y.M.; Li, Y.H.; Cai, S.J.; Yin, X.B.; He, X.W.; Zhang, Y.K. Fluorescent Imaging-Guided Chemotherapy-andPhotodynamic Dual Therapy with Nanoscale Porphyrin Metal-Organic Framework. Small 2017, 13, 1603459. [CrossRef]

5. Zheng, X.; Wu, W.; Zheng, Y.; Ding, Y.; Xiang, Y.; Liu, B.; Tong, A. Organic Nanoparticles with Persistent Luminescence for In Vivo Afterglow Imaging-Guided Photodynamic Therapy. Chemistry 2021, 27, 6911-6916. [CrossRef]

6. Wei, Q.; Chen, Y.; Ma, X.; Ji, J.; Qiao, Y.; Zhou, B.; Ma, F.; Ling, D.; Zhang, H.; Tian, M.; et al. High-Efficient Clearable Nanoparticles for Multi-Modal Imaging and Image-Guided Cancer Therapy. Adv. Funct. Mater. 2018, 28, 1704634. [CrossRef]

7. Yu, W.; Yu, N.; Wang, Z.; Li, X.; Song, C.; Jiang, R.; Geng, P.; Li, M.; Yin, S.; Chen, Z. Chitosan-mediated green synthesis and folic-acid modification of CuS quantum dots for photoacoustic imaging guided photothermal therapy of tumor. J. Colloid Interface Sci. 2019, 555, 480-488. [CrossRef] 
8. William, J.; Rieter, K.M.L.T.; Lin, W. Surface Modification and Functionalization of Nanoscale Metal-Organic Frameworks for Controlled Release and Luminescence Sensing. J. Am. Chem. Soc. 2007, 129, 9852-9853.

9. Yin, H.-Q.; Cao, P.-P.; Wang, X.-Y.; Li, Y.-H.; Yin, X.-B. Computed Tomography Imaging-Guided Tandem Catalysis-Enhanced Photodynamic Therapy with Gold Nanoparticle Functional Covalent Organic Polymers. ACS Appl. Bio Mater. 2020, 3, $2534-2542$. [CrossRef]

10. Zhang, D.; Gao, A.; Xu, Y.; Yin, X.B.; He, X.W.; Zhang, Y.K. Gd-Al co-doped mesoporous silica nanoparticles loaded with $\mathrm{Ru}($ bpy)(3)(2)(+) as a dual-modality probe for fluorescence and magnetic resonance imaging. Analyst 2014, 139, 4613-4619. [CrossRef]

11. Wang, J.; Gao, Y.; Liu, P.; Xu, S.; Luo, X. Core-Shell Multifunctional Nanomaterial-Based All-in-One Nanoplatform for Simultaneous Multilayer Imaging of Dual Types of Tumor Biomarkers and Photothermal Therapy. Anal. Chem. 2020, 92, 15169-15178. [CrossRef]

12. Minati, L.; Antonini, V.; Dalla Serra, M.; Speranza, G.; Enrichi, F.; Riello, P. pH-activated doxorubicin release from polyelectrolyte complex layer coated mesoporous silica nanoparticles. Microporous Mesoporous Mater. 2013, 180, 86-91. [CrossRef]

13. Chen, W.; Zeng, K.; Liu, H.; Ouyang, J.; Wang, L.; Liu, Y.; Wang, H.; Deng, L.; Liu, Y.N. Cell membrane camouflaged hollow prussian blue nanoparticles for synergistic photothermal-/chemotherapy of cancer. Adv. Funct. 2017, 27, 1605795. [CrossRef]

14. Lin, X.; Fang, Y.; Tao, Z.; Gao, X.; Wang, T.; Zhao, M.; Wang, S.; Liu, Y. Tumor-Microenvironment-Induced All-in-One Nanoplatform for Multimodal Imaging-Guided Chemical and Photothermal Therapy of Cancer. ACS Appl. Mater. Interfaces 2019, 11, 25043-25053. [CrossRef]

15. Furukawa, H.; Cordova, K.E.; O'Keeffe, M.; Yaghi, O.M. The Chemistry and Applications of Metal-Organic Frameworks. Science 2013, 341, 1230444. [CrossRef]

16. Kirchon, A.; Feng, L.; Drake, H.F.; Joseph, E.A.; Zhou, H.C. From fundamentals to applications: A toolbox for robust and multifunctional MOF materials. Chem. Soc. Rev. 2018, 47, 8611-8638. [CrossRef]

17. Zhou, H.-C.; Kitagaw, S. Metal-Organic Frameworks (MOFs). Chem. Soc. Rev. 2014, 43, 5415. [CrossRef]

18. Jiang, Z.; Xu, X.; Ma, Y.; Cho, H.S.; Ding, D.; Wang, C.; Wu, J.; Oleynikov, P.; Jia, M.; Cheng, J.; et al. Filling metal-organic framework mesopores with TiO2 for CO2 photoreduction. Nature 2020, 586, 549-554. [CrossRef]

19. Wang, Q.; Astruc, D. State of the art and prospects in metal-organic framework (MOF)-based and MOF-derived nanocatalysis. Chem. Rev. 2019, 120, 1438-1511. [CrossRef]

20. Mohamed Eddaoudi, J.K.; Rosi, N.; Vodak, D.; Wachter, J.; O’Keeffe, M.; Omar, M.; Yaghi, O.M. Systematic Design of Pore Size and Functionality in Isoreticular MOFs and Their Application in Methane Storage. Science 2002, 295, 469. [CrossRef]

21. Cao, Y.; Wang, L.; Shen, C.; Wang, C.; Hu, X.; Wang, G. An electrochemical sensor on the hierarchically porous Cu-BTC MOF platform for glyphosate determination. Sens. Actuators B 2019, 283, 487-494. [CrossRef]

22. Wang, Y.M.; Xu, Y.; Yang, Z.R.; Zhang, X.; Hu, Y.; Yang, R. Multi-functional lanthanide coordination polymers for multi-modal detection of nitroaromatics and trace water in organic solvents. J. Colloid Interface Sci. 2021, 598, 474-482. [CrossRef]

23. Ni, K.; Lan, G.; Veroneau, S.S.; Duan, X.; Song, Y.; Lin, W. Nanoscale metal-organic frameworks for mitochondria-targeted radiotherapy-radiodynamic therapy. Nat. Commun. 2018, 9, 4321. [CrossRef]

24. Lu, K.; Aung, T.; Guo, N.; Weichselbaum, R.; Lin, W. Nanoscale Metal-Organic Frameworks for Therapeutic, Imaging, and Sensing Applications. Adv. Mater. 2018, 30, 1707634. [CrossRef]

25. Wang, Y.-M.; Liu, W.; Yin, X.-B. Self-Limiting Growth Nanoscale Coordination Polymers for Fluorescence and Magnetic Resonance Dual-Modality Imaging. Adv. Funct. Mater. 2016, 26, 8463-8470. [CrossRef]

26. He, C.; Lu, K.; Liu, D.; Lin, W. Nanoscale Metal-Organic Frameworks for the Co-Delivery of Cisplatin and Pooled siRNAs to Enhance Therapeutic Efficacy in Drug-Resistant Ovarian Cancer Cells. J. Am. Chem. Soc. 2014, 136, 5181-5184. [CrossRef]

27. Horcajada, P.; Chalati, T.; Serre, C.; Gillet, B.; Sebrie, C.; Baati, T.; Eubank, J.F.; Heurtaux, D.; Clayette, P.; Kreuz, C.; et al. Porous metal-organic-framework nanoscale carriers as a potential platform for drug delivery and imaging. Nat. Mater. 2009, 9, 172-178 [CrossRef]

28. Lawson, H.D.; Walton, S.P.; Chan, C. Metal-Organic Frameworks for Drug Delivery: A Design Perspective. ACS Appl. Mater. Interfaces 2021, 13, 7004-7020. [CrossRef]

29. Chen, R.; Zhang, J.; Chelora, J.; Xiong, Y.; Kershaw, S.V.; Li, K.F.; Lo, P.K.; Cheah, K.W.; Rogach, A.L.; Zapien, J.A.; et al. Ruthenium (II) complex incorporated UiO-67 metal-organic framework nanoparticles for enhanced two-photon fluorescence imaging and photodynamic cancer therapy. ACS Appl. Mater. Interfaces 2017, 9, 5699-5708. [CrossRef] [PubMed]

30. Wang, Y.M.; Liu, W.; Yin, X.B. Multifunctional mixed-metal nanoscale coordination polymers for triple-modality imaging-guided photodynamic therapy. Chem. Sci. 2017, 8, 3891-3897. [CrossRef]

31. Huang, H.; Yu, B.; Zhang, P.; Huang, J.; Chen, Y.; Gasser, G.; Ji, L.; Chao, H. Highly Charged Ruthenium(II) Polypyridyl Complexes as Lysosome-Localized Photosensitizers for Two-Photon Photodynamic Therapy. Angew. Chem. Int. Ed. 2015, 54, 14049-14052. [CrossRef]

32. Kong, X.J.; Lin, Z.; Zhang, Z.M.; Zhang, T.; Lin, W. Hierarchical Integration of Photosensitizing Metal-Organic Frameworks and Nickel-Containing Polyoxometalates for Efficient Visible-Light-Driven Hydrogen Evolution. Angew. Chem. Int. Ed. 2016, 55, 6411-6416. [CrossRef] [PubMed]

33. Wang, C.; deKrafft, K.E.; Lin, W. Pt nanoparticles@photoactive metal-organic frameworks: Efficient hydrogen evolution via synergistic photoexcitation and electron injection. J. Am. Chem. Soc. 2012, 134, 7211-7214. [CrossRef] [PubMed] 
34. Wang, X.; Chen, L.; Bai, Z.; Zhang, D.; Guan, J.; Zhang, Y.; Shi, C.; Diwu, J. In Vivo Uranium Sequestration using a Nanoscale Metal-Organic Framework. Angew. Chem. 2021, 133, 1670-1674. [CrossRef]

35. Tan, Y.; Sun, D.; Yu, H.; Yang, B.; Gong, Y.; Yan, S.; Chen, Z.; Cai, Q.; Wu, Z. Crystallization mechanism analysis of noncrystalline Ni-P nanoparticles through XRD, HRTEM and XAFS. CrystEngComm 2014, 16, 9657. [CrossRef]

36. Liu, J.; Bu, J.; Bu, W.; Zhang, S.; Pan, L.; Fan, W.; Chen, F.; Zhou, L.; Peng, W.; Zhao, K. Real-time in vivo quantitative monitoring of drug release by dual-mode magnetic resonance and upconverted luminescence imaging. Angew. Chem. 2014, 126, 4639-4643. [CrossRef]

37. Yuan, Y.; Zhang, C.J.; Xu, S.; Liu, B. A self-reporting AIE probe with a built-in singlet oxygen sensor for targeted photodynamic ablation of cancer cells. Chem. Sci. 2016, 7, 1862-1866. [CrossRef]

38. Fateminia, S.A.; Kacenauskaite, L.; Zhang, C.J.; Ma, S.; Manghnani, P.N.; Chen, J.; Xu, S.; Hu, F.; Xu, B.; Lauren, B.W.; et al. Simultaneous increase in brightness and singlet oxygen generation of an organic photosensitizer by nanocrystallization. Small 2018, 14, 1803325. [CrossRef]

39. Huang, P.; Wang, W.; Zhou, J.; Zhao, F.; Zhang, Y.; Liu, J.; Liu, J.; Dong, A.; Kong, D.; Zhang, J. Amphiphilic polyelectrolyte/prodrug nanoparticles constructed by synergetic electrostatic and hydrophobic interactions with cooperative $\mathrm{pH}-$ sensitivity for controlled doxorubicin delivery. ACS Appl. Mater. Interfaces 2015, 7, 6340-6350. [CrossRef]

40. Podila, R.; Brown, J.M. Toxicity of engineered nanomaterials: A physicochemical perspective. J. Biochem. Mol. Toxicol. 2013, 27, 50-55. [CrossRef]

41. Liu, Y.; Sun, D.; Fan, Q.; Ma, Q.; Dong, Z.; Tao, W.; Tao, H.; Liu, Z.; Wang, C. The enhanced permeability and retention effect based nanomedicine at the site of injury. Nano Res. 2020, 13, 564-569. [CrossRef]

42. Marsh, S.R.; Pridham, K.J.; Jourdan, J.; Gourdie, R.G. Novel Protocols for Scalable Production of High Quality Purified Small Extracellular Vesicles from Bovine Milk. Nanotheranostics 2021, 5, 488-498. [CrossRef] [PubMed] 